This section addresses the fixity and motion of migration in two broad areas. The first is the idea of identities in motion, in flux. This idea has been the habitat of anthropologists for decades. How do migrants and refugees make sense of the new world that they inhabit, and the process by which they have come to be in a new place? Who are they now, what does community look like, what are the relationships between the past, the present, and the future, when a person is supplanted in a new culture, place, and climate? The other aspect is the precarity of migrants and asylum seekers when they are in motion, when they find themselves temporary, in transit, struggling to attain a better position in the global economy or even just to survive. The precarity of migrants away from social structures and the known is magnified and multiplied under indifferent, exclusionary, and hostile host settings. In both senses, migration becomes a space of making and remaking worlds and identities. The articles in this section reveal how, even on multiple planes of choice and necessity for survival, migration is a site of incredible creativity, strategy, and unexpected connections.

Keywords: migration; anthropology; adaptation; improvisation; creativity

\title{
INTRODUCTION
}

This special section addresses two of the major themes in migration research within anthropology. The first three articles explore migrants building identity and community in New Zealand. Merino Ortiz's article queries how migrants with refugee origins make sense of their lives and build relationships in a new locale. Finlayson's article adds a timely exploration of South African 
migrants' struggles with the tensions between identity and assimilation. Brown Pulu, Mukhtar, and Singh bring a close perspective to the ways that Punjabi migrant communities in New Zealand have come together in the wake of the Christchurch terrorist attack this year, drawing on a shared history that is rearticulated in a migrant setting. Lennox's, and López Marín and Lenti's articles both highlight the precarity of migrants as they manage their liminal existence. The demands of improvisation and adaptation for the sake of survival highlight the extreme measures that some populations must adopt in order to survive, and for the sake of their family from which they may be separated. Constraints to migrant experiences come from official and unofficial sources, as do resources that enable the journeys. The articles in this special section all highlight that international migration demands adaptation on the part of the migrant to succeed or at times just to survive.

Early migration studies in the 1970 os-80s focused primarily on migration as a site where ethnic, national, and cultural identities were constructed, maintained, hybridised, transmitted, and renegotiated (Stojic-Mitrovic 2018; Werbner and Johnson 2011). Questions related to cultural identity and its role in migrant lives in permanent and temporary migratory journeys continue to be central to anthropological considerations. These topics have frequently also been central to migrants and migrant communities, as in Brown Pulu, Mukhtar, and Singh's study, as they consciously negotiated and shaped their lives in order to maintain cultural values and traditions. Reconstituting community implies both continuity and re-creating of home culture, relationships, and identities, themes that come to the forefront in Finlayson and Merino Ortiz's articles. The necessity of learning new skills for adaptation highlights how 'place-making for the displaced is marked by uncertainty and creative engagement' (Datta 2019), themes that run across these diverse articles.

Although place as intimately connected with culture has shaped the foundations of anthropology, current thought and migration research has come to emphasise the changing, mediated, and mobile aspects of culture (Hinkson 2017, 53; Stojic-Mitrovic 2018). Migration research has emphasised the fluidity both of societies, people, and ideas, and of the unfolding aspects of culture in how people live and adapt their lives in real time to the place they are in. Anthropology contributes a unique ability to identify and render visible those, such as the temporary or irregular migrants of Lennox's, and López Marín and Lenti's studies, outside of dominant social structures and permanent community. While migration was once viewed as a linear journey from 'here to there', the complicated and multi-directional journeys of migrant lives such as step 
migration, return migration, repeat migration, as well as multiple near and distant relationships, reveal the intricacies and diversity of migrant experiences (Feldman-Bianco 2018, 204; Hillmann, Naerssen, and Spaan 2019, 200). In this special section, the authors explore multiple migrant experiences over continuums of choice and force, temporariness and permanence, and economic necessity and personal decisions.

The state is no longer considered a neutral background, but an active and often contradictory force in migrants' lives, a topic explored in Halstead's (2019) book reviewed in this special section. Lennox's article highlights how migration is not only a personal choice and journey but happens along predetermined pathways, and within predetermined limits. As such, studies of mobility have also emphasised the multiple forces that control, block, allow, or constrain movement. López Marín and Lenti's article confirms the regulatory role that states play in migrants' lives, particularly when outside of its regulations the state becomes another of the many obstacles. In contrast, official refugees in Merino Ortiz's study have access to both formal and informal support networks that are out of reach to irregular migrants. Brown Pulu, Mukhtar, and Singh point out how the partition between Pakistan and India has created a social divide along this border, which is partially undone in migrant community relationships abroad in New Zealand. This highlights a strength of close research with migrants to 'challenge statist discourses' which define certain populations according to their relationship to the nation state - such as migrants as by their visa category - and to reveal community, movement, and connections which transcend national limits and definitions (Han 2018,340).

Free movement in migration is perhaps the antithesis to the ethnic-nationalist politics, based on identities and hierarchies imagined as fundamental and fixed to a physical space, finding a resurgence in multiple iterations globally (Renes 2017). Migration, and the current global resistance and hostility toward migration, is perhaps representative of the modern understandings of globalisation. However, despite the rhetoric, migration has continued at just over three per cent of the world's population for decades and remains lower than other times in history such as peaks of colonial expansion (Hillmann, Naerssen, and Spaan 2019). Migration continues to be a central point of inquiry into global processes where global tensions, flows, and interactions are embodied in the lives of those who move across place, space, and political borders. Migration research has increasingly become entwined with theories of globalisation, and migrants' experiences have become emblematic of widespread global connections, as well as global inequalities. 
Anthropologists have highlighted that labour migration as an economic strategy is often highly precarious and unequally positioned in the global economy, despite being a necessary survival strategy for many migrants. Researchers concerned with human trafficking and related forms of labour exploitation have pointed out that the history of migration control is a history of the control of labour, particularly the most controlled, indentured, and exploited labour (Sharma 2018; Sussman 2018). Migrant workers continue to be frequently positioned as marginalised, disposable, and discardable, bearing greater risks for injury and finding extra barriers in place between accessing benefits and health care in the case of injuries or injustices (Flynn 2018; Han 2018). López Marín and Lenti's, and Lennox's articles highlight the precarity of economic and labour migrants in navigating both economic and procedural barriers in accessing work and the basics of life. Migrant labourers often face a double exclusion - from work at all, and from all but the most exploitative jobs, protections, and working conditions.

There is an ongoing challenge in theorising the constrained conditions that migrants often face while maintaining the personal context, and the agency that migrants display in navigating and creating success within difficult circumstances. Anthropology also demands maintaining a sense of participants own understandings of their situations (Yelvington 2019). Theorising 'underclasses' can be justification for control and interventions (Barrios 2017; StojicMitrovic 2018, 5); indeed, pointing out the vulnerability of migrants to abuses in the form of human trafficking has in numerous cases justified the control of (predominantly women) migrants' movement, creating further exclusions from economic opportunities (Barrios 2017, 159; Hwang 2017). Freedom and unfreedom, exploitation, choice, constraints, opportunity, and strategy are all part of the theoretical landscape as researchers make sense of the complexities of labour, as shaped by personal and structural factors, in migration and migrant lives. López Marín and Lenti, and Lennox, explore migrants' improvisations, avoiding the trope of the 'victim' while calling attention to the real and pervasive injustices, inequalities and hardships that migrants face.

The politics of migration has drawn on the idea of crisis as a framing for issues related to migration. However, anthropologists have pointed out that moments of crisis emerge from the ordinary workings of society, and that framing a crisis as an exception can obscure the normal operations that lead to crises moments (Barrios 2017; Hinkson 2017; Stoler 2013). Asylum seekers, for example, are undoubtedly experiencing a crisis in their lives, which reveals wider structural crises. The political definitions, however, may be quite far from 
their own analysis, and may instead point to the way that their movement is creating a crisis for other people or political institutions. Brown Pulu, Mukhtar, and Singh's article explores the idea of crisis in another aspect, how moments of crisis have created and reconfigured a sense of community among Punjabi migrants in New Zealand in different ways from their origin. Merino Ortiz's work with former refugees to New Zealand suggests the sense of crisis that has shaped their journeys and their ongoing relationships to their places of origin. López Marín and Lenti highlight how crises that led to people leaving their homes and becoming irregular migrants had also led to ongoing risk and further moments of crisis, again challenging the notion of crisis as exception.

As anthropologists themselves frequently conduct fieldwork as migrants, research on movement across physical and cultural distance implies a unique and intimate relationship with the practice of anthropology. It suggests a close examination of the purposeful adaptation of body, mind, and communication, the physical movement, distance, and displacement, and the experience of being an 'unsettled subject' frequently characterising both migrants' and anthropologists' lives in new locations (Sørensen and Olwig 2003, 248). Finlayson's article highlights an important aspect of migration research for anthropologists - the fact that migrants themselves often perform anthropological comparisons in their process of adaptation. Confronted with a social reality different from one's own can force deeply held and unconscious beliefs to come to the surface and be articulated. As such, migrants' embodied experiences are further informative to the practice of anthropology and the comparative reflexivity that cross-cultural study demands.

\section{OVERVIEW OF SPECIAL SECTION}

Merino Ortiz's article describes how cultural practices and values are modified and applied to refugees' resettlement process and to building new relationships and communities. She describes how Colombian former refugees use the notion of voluntariado to meet each other's needs, and to quantify and value the multiple forms of support that new arrivals depend on to adapt to resettlement. Even among Colombian and other Latin American migrants, the process of resettlement demands creating new ways of relating to and understanding the world and society. It also demands new skills and creating a new social identity, and Merino Ortiz points out the importance of voluntariado networks in accessing skills, resources, and social support. She also highlights that beyond the indebtedness implied by giving relationships, this process creates and strengthens meaningful relationships among the givers and recipients of voluntariado. 
Finlayson's article focuses on the issue of personal and cultural identity in the context of migration. His participants, Afrikaner migrants to NZ, shared a strong sense of what it means to be an Afrikaner - yet, they themselves did not necessarily embody all the traits and practices which they identified as central. His work highlights the role of anthropology in understanding the relationships between deeply held ideals and the actual practice of life. Adapting to a new community places significant demands on migrants to not only create new practices and relationships, but to reconsider their relationship to their own culture and worldviews that can no longer be taken for granted. South African, and Afrikaner, identity is based on a complicated and often violent history, and in the context of migration the contradictions and ambiguities of cultural identity come to the forefront for Finlayson's participants who are attempting to reinvent themselves as migrants to NZ.

Brown Pulu, Mukhtar, and Singh's article demonstrates how history, culture, and diasporic identity have converged in a moment of crisis to create a sense of community which may be quite different from that experienced by nonmigrants at home. They argue that in diasporic identity, the borders established by the partition between India and Pakistan are transcended by migrants with a shared cultural and historic background despite the present separation between non-migrants on either side of the border. As such, they explore the possibilities of migrant experience to repair, challenge, and re-narrate cultural identity. In contrast to many studies of migrant identity in relation to their homeland, this article does not suggest cultural loss or hybridity, but a renegotiation of the migrant's home history and community. This article is also an account of research, the identity work that underpins insider research, and the complexity and personal involvement in the challenge of 'privileging the native, the insider's voice, and the vernacular'.

Lennox's article describes the juncture between the dominant policies and narratives on migration, and Filipino labour migrants' actual experiences. Migration is, in the Philippines, presented as a linear and accessible path to success in the form of well-paid work overseas. However, Lennox's participants found that the migration pathway is highly precarious with the potential for failure at many points. This precarity also demands that migrants improvise strategies to overcome these potential ruptures of their migrant journeys, demonstrating how failure and challenges must be managed in individualised ways. These accounts demonstrate how, despite the programs and policies designed to support migrants and promote migration, Filipino labour migrants are highly precarious not only as low-status global workers but in their ability to access and benefit from migrant labour opportunities. 
López Marín and Lenti's article highlights the extreme conditions that 'irregularised' trans-Mexican migrants from (primarily) South America face in their journeys towards the United States. They point out the immense creativity, agency, and strategy that migrants must develop and deploy in order to undertake and survive their journeys. This article also highlights how irregular migrants represent a subversive challenge to the politics of migration control. Multiple, overlapping dangers demonstrate the social violence that maintains the marginalisation and lack of protection for migrants, particularly irregular migrants. Nevertheless, the strategies that migrants employ to avoid legal structures are often extreme versions of processes that many migrants go through in more ordinary journeys. Examples include adapting one's speech and dress, learning new ways of being, renegotiating the home cultural identity, and forging new relationships. However, under these conditions and the very real threats of violence, incarceration, or deportation, these skills become necessary for day to day survival.

\section{CONCLUSIONS}

One of the ongoing challenges to anthropology in the face of globalisation is how to make sense of local lives, lived in-situ day to day, which are very much shaped by larger global forces. While migrant journeys represent individual choices and plans, they also demonstrate global processes and structural crises. However, a holistic and critical view of labour migration challenges the dominant economic focus and reveals that degrees of economic success are not the entirety of the migrant experience or motivations (Abélès, Haince, and Rousseau 2017, 81). Further, close accounts highlight the complex and creative strategies that migrants deploy in the face of economic struggle. The tensions between theory and practice, and between economic trends and flows on regional and global scales, and the minutiae and bounded relational interactions of daily life, are exemplified in the anthropology of migration.

Migration research continues to inhabit the place of tension between theorising and exploring global connections and macro-level processes, and attending to the detailed, messy, contradictory, and close-up perspective of daily lived experience. Anthropologists have been critical of macro-level theories that may make more sense on a theoretical level than they do in making sense of peoples' day to day existences (Han 2018; Ingold 2014). Migrant lives offer new ways of considering global processes, but there are continuing questions about the limits of creating theories that go beyond the particularity of ethnographic accounts (Das 2015; Han 2018). Amid these ongoing debates, anthropology continues to offer a unique perspective in attempting to bring the concept of 
globalisation back to actual experience, exploring the ordinary and mundane ways that people forge and maintain connections, and how people experience the connectedness of their world.

Migration and globalisation have presented challenges to anthropology and to the traditional fieldwork practices which depended on deep immersion in a society in a specific place. Multiple strategies have emerged to address these challenges, such as multi-sited ethnography, mobile ethnography, and virtual ethnography. The articles contained, however, rely on traditional single-sited fieldwork but demonstrate the insight into global connections and global movements which are accessible through singular deep engagements. Anthropology maintains the role of offering glimpses of the ordinary, the eating, drinking, and working, that make up life and the person of 'the migrant', rather than the category, image, or statistic.

\section{REFERENCES}

Abélès, Marc, Marie-Claude Haince, and Phillip Rousseau. 2017. Thinking beyond the State. Ithaca, New York: Cornell University Press.

Barrios, Roberto E. 2017. 'What Does Catastrophe Reveal for Whom? The Anthropology of Crises and Disasters at the Onset of the Anthropocene'. Annual Review of Anthropology 46 (1):151-66.

Das, Veena. 2015. 'What Does Ordinary Ethics Look Like?' In Four Lectures on Ethics: Anthropological Perspectives. Masterclass 3. Chicago, IL: HAU Books.

Datta, Ankur. 2019. “"That Was Natural. This Is Just Artificial!”: Displacement, Memory, Worship, and Connection at a Kashmiri Hindu Shrine Replica?. History and Anthropology 30 (3):276-92.

Feldman-Bianco, Bela. 2018. 'Anthropology and Ethnography: The Transnational Perspective on Migration and Beyond'. Etnografica 22 (1) (February): 195-215.

Flynn, Michael A. 2018. Im/Migration, Work, and Health: Anthropology and the Occupational Health of Labor Im/Migrants: Anthropology of Work Review' Anthropology of Work Review 39 (2):116-23.

Halstead, Narmala. 2019. Competing Power: Landscapes of Migration, Violence and the State. New York: Berghahn Books. 
Han, Clara. 2018. 'Precarity, Precariousness, and Vulnerability'. Annual Review of Anthropology 47 (1):331-43.

Hillmann, Felicitas, A.L. van Naerssen, and Ernst Spaan, eds. 2019. Trajectories and Imaginaries in Migration: The Migrant Actor in Transnational Space. Studies in Migration and Diaspora. London; New York, NY: Routledge.

Hinkson, Melinda. 2017. 'Precarious Placemaking. Annual Review of Anthropology 46 (1): 49-64.

Hwang, Maria. 2017. ‘Offloaded: Women's Sex Work Migration across the South China Sea and the Gendered Antitrafficking Emigration Policy of the Philippines'. WSQ: Women's Studies Quarterly 45 (1-2):131-47.

Ingold, Tim. 2014. 'That's Enough about Ethnography!' HAU: Journal of Ethnographic Theory $4(1): 383-95$.

Renes, Cornelis Martin. 2017. 'Living on the Borders of Belonging: An Editorial Note. Coolabah 21 (2017):1-5.

Sharma, Nandita. 2018. 'Immigration Restrictions and the Politics of Protection'. In Revisiting Slavery and Antislavery: Towards a Critical Analysis, edited by Laura Brace and Julia O'Connell Davidson, 123-47. New York, NY: Springer Berlin Heidelberg.

Sørensen, Ninna Nyberg, and Karen Fog Olwig, eds. 2003. Work and Migration: Life and Livelihoods in a Globalizing World. Transnationalism 4. London; New York: Routledge.

Stojic-Mitrovic, Marta. 2018. 'Migration as the Object of the Anthropological Inquiry: Conceptualizations and Policies'. Glasnik Etnografskog Instituta $66(3): 459-75$.

Stoler, Ann Laura, ed. 2013. Imperial Debris: On Ruins and Ruination. Durham; London: Duke University Press.

Sussman, Charlotte. 2018. 'Historicizing Freedom of Movement: Memory and Exile in Political Context'. In Revisiting Slavery and Antislavery: Towards a Critical Analysis, edited by Laura Brace and Julia O'Connell Davidson, 97-122. New York, NY: Springer Berlin Heidelberg. 
Introduction · Lennox

Werbner, Pnina, and Mark Johnson. 2011. Diasporic Journeys, Ritual, and Normativity among Asian Migrant Women. London: Routledge.

Yelvington, Kevin A. 2019. “The Misery of Being Exploited by Capitalists Is Nothing Compared to the Misery of Not Being Exploited at All"?: A Predicament for Applied Anthropology'. Dialectical Anthropology, August. 